\title{
Artificial intelligence and human workers interaction at team level: a conceptual assessment of the challenges and potential HRM strategies
}

\author{
Ahmad Arslan \\ Department of Marketing, Management and IB, University of Oulu, Oulu, Finland \\ Cary Cooper \\ Alliance Manchester Business School, The University of Manchester, Manchester, UK \\ Zaheer Khan \\ Business School, University of Aberdeen, Aberdeen, UK \\ Ismail Golgeci \\ Department of Business Development and Technology, Aarhus University, \\ Herning, Denmark, and \\ Imran Ali \\ School of Business and Law, Central Queensland University, Melbourne, Australia
}

\begin{abstract}
Purpose - This paper aims to specifically focus on the challenges that human resource management (HRM) leaders and departments in contemporary organisations face due to close interaction between artificial intelligence (AI) (primarily robots) and human workers especially at the team level. It further discusses important potential strategies, which can be useful to overcome these challenges based on a conceptual review of extant research.

Design/methodology/approach - The current paper undertakes a conceptual work where multiple streams of literature are integrated to present a rather holistic yet critical overview of the relationship between AI (particularly robots) and HRM in contemporary organisations.

Findings - We highlight that interaction and collaboration between human workers and robots is visible in a range of industries and organisational functions, where both are working as team members. This gives rise to unique challenges for HRM function in contemporary organisations where they need to address workers' fear of working with AI, especially in relation to future job loss and difficult dynamics associated with building trust between human workers and AI-enabled robots as team members. Along with these, human workers' task fulfilment expectations with their AI-enabled robot colleagues need to be carefully communicated and managed by HRM staff to maintain the collaborative spirit, as well as future performance evaluations of employees. The authors found that organisational support mechanisms such as facilitating environment, training opportunities and ensuring a viable technological competence level before organising human workers in teams with robots are important. Finally, we found that one of the toughest challenges for HRM relates to performance evaluation in teams where both humans and AI (including robots) work side by side. We referred to the lack of existing frameworks to guide HRM managers in this concern and stressed the possibility of taking
\end{abstract}

(C) Ahmad Arslan, Cary Cooper, Zaheer Khan, Ismail Golgeci and Imran Ali. Published by Emerald Publishing Limited. This article is published under the Creative Commons Attribution (CC BY 4.0) licence. Anyone may reproduce, distribute, translate and create derivative works of this article (for both commercial and non-commercial purposes), subject to full attribution to the original publication and authors. The full terms of this licence may be seen at http://creativecommons.org/licences/by/4.0/ legalcode

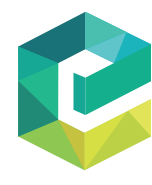

International Journal of Manpower Vol. 43 No. 1, 2022 Emerald Publishing Limited $0143-7720$ DOI 10.1108/IJM-01-2021-0052 
IJM

43,1

insights from the computer gaming literature, where performance evaluation models have been developed to analyse humans and AI interactions while keeping the context and limitations of both in view.

Originality/value - Our paper is one of the few studies that go beyond a rather general or functional analysis of AI in the HRM context. It specifically focusses on the teamwork dimension, where human workers and AI-powered machines (robots) work together and offer insights and suggestions for such teams' smooth functioning.

Keywords Artificial intelligence, HRM strategies, e-HRM challenges, Human-robot interaction, Teamwork Paper type Research paper

\section{Introduction}

The implications of technological developments and innovations for humans are increasingly becoming complex, with the role of machines changing from useful tools for production or usage to playing a critical role in different spheres of organisational and economic life (e.g. Coupe, 2019; Arslan et al., 2021). Work in modern society propelled by progressively prevalent digitalisation and communication technology comprises non-stop connectivity, immediacy and a plethora of challenges in the work-life (Derks et al., 2015). As such, work-life and work identified are being fundamentally transformed and reconfigured amidst the growing prevalence of new emerging digital economy and emergent technologies such as big data, machine learning and artificial intelligence (AI) attached to the newly emerging digital economy (Petriglieri et al., 2019; Sutherland et al., 2020).

Recent research offers extensive evidence of different ways in which managers and workers operate in a complex environment characterised by swift digital interactions, fast cycle times (Golembiewski, 2019), technological intensity (Serban et al., 2015) and the gig economy (Petriglieri et al., 2019; Sutherland et al., 2020). A perfect storm of technological change is shifting the landscape in which managers and employees operate. The rhetoric is overwhelming in the popular press about the benefits as well as challenges (dark side) of utilising modern technologies in the workplace. In this context, a recent Forbes article highlighted that the future of HR is both digital and human (Forbes, 2019), thus suggesting a vital role of modern technologies in HRM function. In this context, recently several concerns have been raised by the scholars about the potential dark-sides of emerging technologies such as AI-based analytics within the HRM functions (cf. Davison et al., 2011; Gibbs et al., 2015; Holland and Bardoel, 2016; van den Heuvel and Bondarouk, 2017) Multidimensional technological forces involving augmented reality, machine learning, Industry 4.0, the Internet of things, big data, AI and blockchain are profoundly transforming work and organisations (Avolio et al., 2014; Mohanta et al., 2020; Peysakhovich and Naecker, 2017). Digital technologies have become a new strategic imperative for businesses (Fitzgerald et al., 2014). As such, managers and employees increasingly behave in unconventional ways and are compelled to use social media, algorithms, big data analytics, machine learning, simulations, augmented reality and games in their everyday lives and as part of their decision-making processes (Serban et al., 2015; Spencer et al., 2012). As these digital technologies radically transform leaders' work environment, scholarly attention has mostly focussed on the effects of particular technologies on organisations and their leaders (Henfridsson et al., 2014; Spencer et al., 2012).

Rapid technological change, especially in the digital age (Henfridsson et al., 2014), constantly feeds the gap between human workers' current and expected levels of knowledge and competencies. Information overload can exacerbate managers and employees' anxiety and personal paradoxes (e.g. Bawden and Robinson, 2009). However, not keeping up with the required knowledge and competence levels may lead to an overwhelming gap between the actual and required human competitiveness levels. Furthermore, the constant flux of new technologies and paradigms makes most existing skills obsolete and weakens the justification for building new competencies that could become irrelevant virtually 
overnight (Anand et al., 2010; Henfridsson et al., 2014). As such, adjusting to technological change in the current age is a daunting challenge.

In human resource management (HRM), like other management domains, emerging technologies, including AI, have become a visible player going beyond their role as just a tool (Ivanov and Webster, 2019; Malik et al., 2020; Vrontis et al., 2021). AI consists of a broad set of technologies that allow the computer to perform multiple tasks that normally require human cognition, including adaptive decision-making (e.g. Tambe et al., 2019; Vrontis et al., 2021). It is in such a context that previous research has shown how AI influences specific HR tasks, for instance, how to use data mining techniques in employee selection, intelligent agent technologies for employee development, new employee recruiting through social networking sites by using data extraction tools, smart sensory mechanisms to evaluate employee productivity and detect knowledge hiding (Strohmeier and Piazza, 2015; Richards et al., 2019; Malik et al., 2020). However, so far, the focus of extant research on AI's role for HRM has been on its application at a functional level. An interesting dimension of $\mathrm{AI}$ in recent years has manifested itself in the visibility of AI-powered machines including robots interacting and collaborating with human workers in a range of tasks from industrial production (e.g. Libert et al., 2020) to product development (e.g. Demir et al., 2020), and customer service delivery (Ivanov and Webster, 2019).

We specifically focus on the challenges that HRM function in contemporary organisations face due to close interaction between AI (robots as well as processes) and human workers, especially at the team level, and highlight vital potential strategies, which can be useful to overcome these challenges. By doing so, we contribute to the extant HRM as well as technology management literature in three important ways. First, we highlight the key challenges and opportunities arising from utilising emerging technologies in the workplace. These challenges and opportunities could seem overwhelming at face value. However, we argue that a closer engagement between social and technological sciences can enable alleviating the challenges and better utilising the potential opportunities of the rise of new technologies in the workplace. Second, we highlight the key psychological aspects particularly trust by building on recent studies (e.g. Glikson and Woolley, 2020; Webster and Ivanov, 2020; Gillath et al., 2021) as important enablers in facilitating AI-human worker interaction in organisations. Only by establishing and maintaining trust in $\mathrm{AI}$ and other emergent technologies can it be possible to make advances in HRM that contribute to all stakeholders, including employees and shareholders. Finally, we document the important role of training and sound HR practices in enhancing the integration of emerging technologies in organisations while maintaining privacy and security of employees' personal data. We suggest that training and rigorous HR practices can both support trust in emerging technologies and their effective leverage in the workplace.

The rest of the paper is organised as follows. The next section presents a specific discussion on the influences of $\mathrm{AI}$ on $\mathrm{HR}$ functions in contemporary organisations. This is followed by a discussion on the challenges posed by AI's rise for HR functions and strategies. Finally, the paper concludes with the presentation of theoretical, managerial and policy implications as well as future research directions.

\section{AI and HRM: an overview}

$\mathrm{AI}$ is a crucial and fundamentally transformative new technology that can be defined in various ways. However, generally speaking, it corresponds to a machine-based system's ability to correctly interpret external data, learn from it, flexibility use and adapt that knowledge to achieve specific goals and fulfil tasks (e.g. Kaplan and Haenlein, 2019). Nowadays, first-generation AI (applying AI only to specific tasks) is a commonplace phenomenon across a range of organisations. It is increasingly being argued that in the near
$\mathrm{AI}$ and human workers interaction 
IJM

43,1

future, first-generation AI will evolve into what is called artificial general intelligence that is expected to be able to reason, plan and solve problems autonomously for tasks they were never even designed for (e.g. Kaplan and Haenlein, 2019). Artificial general intelligence is likely to challenge some of the white-collar tasks but is not likely to pose a fundamental threat to modern management's uniquely human aspects such as social interactions with workers, as well as managers and employees' emotional intelligence. That said, in the longer run, artificial general intelligence may be followed by an artificial superintelligence, where self-aware and conscious machines-based systems are expected to depict scientific creativity, social skills and general wisdom, which has so far been associated with humans (Yampolskiy, 2015). Such developments have the potential to render humans redundant. Artificial superintelligence is probably the stage where humans and human work will be fundamentally challenged and either be transformed or evaporated, leading to serious implications for employees' productivity and retention. The emergence of recent AI-based technologies, such as autoregressive language models like Generative Pre-trained Transformer-3 (GPT) (Analytica, 2020), conversational systems, and immersive technologies (Hudson et al., 2019), hint at unique challenges faced by humanity and employees if/when artificial superintelligence emerges as a prevalent phenomenon.

AI has a wide range of applications within the realm of HRM. For example, AI tools have been applied to the recruitment process to facilitate job application and selection practices (Rodney et al., 2019). Likewise, big data algorithmic analytics, sensory and tracking technologies and metabolism monitors have risen as AI-based decision-making technologies in the workplace (Nica et al., 2019). Furthermore, Industry 4.0 inspired smart HR 4.0 has been applied to transform talent onboarding, talent development and talent offboarding processes in the HRM domain (Sivathanu and Pillai, 2018). These growing potentials of AI for HRM can be seen both as an opportunity for advancement and as a daunting behavioural challenge, especially for those directly at the front line in terms of work-related threats AI poses.

With regard to the challenges associated with AI-related applications in HRM, employees face toxic decision processes and competitive threats amidst the growing prevalence of technology in the workplace (Maitlis and Ozcelik, 2004). Recent research on digital firms highlights that insidious HRM techniques to the detriment of workers' interests are increasingly commonplace (Mosco, 2016). The growing wave of layoffs and redundancies driven by AI and related technologies engenders severe emotional damages for affected professionals and co-workers (survivors) who remain in organisations but most often in a more precarious situation ensuing the wave of technology-driven layoffs and redundancies (Moore, 2018). The downsizing and restructuring in many organisations due to these developments mean that the traditional psychological and social contract, which offered job security in return for organisational loyalty, has changed (Petriglieri et al., 2019). In this vein, even if human labour persists, some major changes, including pervasive rationalisation, maximising the output extracted from labour inputs, and AI-driven replacement of humans in important functions that need large mental capacities, are foreseeable (Pueyo, 2018). In addition, scholarship suggests that HR managers are ill-prepared as most of them lack critical skills and training in modern technology-enabled tools, and this can potentially have consequences for employees and organisations (e.g. Holland and Bardoel, 2016; Mariappanadar and Aust, 2017). There are also issues related to employees and their managers' misuse of IT resources and sharing of information to unintending recipients. Similarly, the security and protection of employees' personal data is a huge challenge for organisations, as misuse of personal information and posting information on websites could potentially harm employees' welfare.

Furthermore, employees face psychological and existential challenges related to dealing with "impossible expectations" amidst relentless technological changes that are accelerated by conditions such as anxiety, stress and burnout (e.g. Harms et al., 2017; Bednar and Welch, 2020). 
In particular, managers and employees may face challenges related to confidence concerning working along with AI-based tools and algorithms, confront constant pressure to change and adapt amidst AI-driven work paradigms and systems and concerns over controlling AI-based machines to avoid autonomous decisions and implicit biases (Kaplan and Haenlein, 2019), as well as potentially overburden with new work requirements. Machine-human interaction in the workplace is likely to bring a plethora of questions and challenges to HRM managers and employees alike. Such interaction and increasing prevalence of AI systems are also likely to shape the way people work and how their performance is measured and managed (Richards et al., 2019). Consequently, AI systems and AI-based tools are inextricably intertwined with HRM and are likely to transform the modern HRM domain through unprecedented levels of potential and future challenges. This intertwining and interaction between AI and humans is also expected to result in significant challenges for organisations' HRM function (e.g. Tambe et al., 2019). The next section discusses these challenges from a critical perspective as well as offers some insights concerning potential HRM strategies.

\section{AI and human workers interaction: challenges and potential HRM strategies}

A significant amount of prior research has focussed on AI's challenges for HRM from the perspective of lost jobs (e.g. Coupe, 2019; Ivanov and Webster, 2019; Arslan et al., 2021), changed professional demands (e.g. Hmoud and Lszlo, 2019), need for new skills development (Malik et al., 2020; Arslan et al., 2021) and talent management dynamics (e.g. Vrontis et al., 2021). KPMG (https://home.kpmg/xx/en/home.html), in their recent report, mentioned that majority of CEOs believe that AI will create more jobs than the ones it eliminates, while the view of the majority of HR managers is opposite (KPMG, 2019, p. 1). A key reason for this difference in perceptions concerning the role of $\mathrm{AI}$ is due to the fact that traditionally, HR function in the organisation has viewed technologies including AI from a functional perspective, and the focus has been on retraining and skills development for the workers whose jobs may be replaced by AI. However, continuous interaction between AI-powered robots and human workers in routine organisational functions (e.g. Libert et al., 2020) is a dynamic that has not been specifically analysed in-depth by the researchers as well as understood better by contemporary HR managers.

It has been argued that due to Industry 4.0 associated technologies, there is increased visibility of interaction and collaboration between humans and AI (usually visible in the form of robots, though increasingly other smart machines are becoming visible to improve productivity), which brings its own unique challenges concerning control, analysis and performance evaluation (e.g. Tsarouchi et al., 2017; Libert et al., 2020). These scholarly insights and popular press indicate that digital technologies, including $\mathrm{Al}$, will play a significant role in HR, and HR leaders need to find ways to optimise the interactions of digital technologies and humans (cf. Forbes, 2019). An interesting example is this concern is of socalled "smart (or social) robots", which have been helping to enhance the industrial process by working together with humans in industrial assembly lines (Evjemo et al., 2020), as well as offering advice to human workers using AI-based algorithms in other organisational functions (Ivanov and Webster, 2019). Hence, the AI-powered robots' role has changed from "tools to teammates" for human workers (Ivanov and Webster, 2019; Seeber et al., 2020). This change has resulted in humans and robots increasingly taking more and more complex and collaborative roles in both the manufacturing and the service sectors (Seeber et al., 2020). Specifically, this interaction and collaboration have been found to be visible in contexts like military, construction, agriculture, medical/healthcare, analytical services and manufacturing (Webster and Ivanov, 2020). Against this backdrop, AI has been suggested to play a vital role in transforming the HR function, and its role is highlighted to be crucial for plugging the skills gaps that organisations are facing (CIO, 2020). Wilson and Daugherty
$\mathrm{AI}$ and human workers interaction 
IJM

43,1
(2018), in their analysis of robot-human co-working in 1,500 organisations, found that they can enhance each other's strengths and increase organisational productivity if the co-working is implemented strategically in the relevant teams. In this regard, they highlight the example of cobot arm being used in Mercedes-Benz production, which enhances the human worker and stress the importance of the development of collaborative intelligence (Wilson and Daugherty, 2018). However, the development of such collaboration is not that straightforward process as some scholars have highlighted that the along with being functional interactions; such endeavours also significantly influence the meaning and meaningfulness of work for the human workers (e.g. Smids et al., 2020).

For HRM studies, enhancing interaction and collaboration between human employees (generally as well as being part of a team) has been a significantly researched topic, given that cognitive biases, emotions, and personality differences play a major role in the success or failure of such collaborations (Mattesich and Monsey, 1992; Driskell et al., 2018; Smids et al., 2020). These aspects become even more complex in those settings and contexts where AI-powered robots and humans are working together as teammates because it is likely that there can be resistance by some human workers due to fear of losing their jobs ultimately to technology (e.g. Ivanov and Webster, 2019; KPMG, 2019; Smids et al., 2020), as well as psychological problems with the adoption of emerging technologies. Similar issues have been addressed in some past studies under the umbrella term "computer or technology anxiety", which has been defined as the extent to which an individual feels unpleasant when using a specific technology (e.g. Mikkelsen et al., 2002). This anxiety manifests itself in an emotional state such as frustration, apprehension, fear and uneasiness (e.g. Okumus et al., 2017). The circumstances surrounding AI-powered machines and processes including robots interacting and collaborating with human workers are very complex compared to relatively old technologies such as personal computers or legacy organisational IT systems. Hence, it is logical to expect that some human workers' anxiety can be higher while dealing with these robots regularly as part of their team. This can influence their acceptance of robots as team members and adopt this new reality in working life. For the HR function in contemporary organisations, this anxiety presents a significant challenge that decision-makers and HR leaders must address carefully and strategically. Prior scholars have referred to taking a state perspective to computer- or technology-related anxiety (Harrington et al., 1990), which means that it can be a temporary phase, and anxiety tends to be higher when the technology is introduced (Webster and Martocchio, 1992; Novak and Wisdom, 2018). Therefore, earlier studies have stressed the importance of clear communication concerning expectations (e.g. Okumus et al., 2017), potential changes in job tasks (Lariviere et al., 2017), training opportunities (e.g. Okumus et al., 2017; Sampson et al., 2020) and adjustment time periods (Arthanat et al., 2019) to overcome this anxiety. We argue that the adoption of similar approaches by HR departments in organisations where human and AI-powered machines and processes are interacting or going to interact regularly can help overcome the barriers and hesitations.

It is further important to note that trust has been highlighted as one of the major issues when working with emerging technologies such as AI (Ivanov and Webster, 2019; Webster and Ivanov, 2020; Gillath et al., 2021). Scholars have highlighted issues such as reliability, availability, confidentiality and integrity as cornerstones for developing trust with technology by humans (Castelfranchi and Falcone, 2010). This trust ultimately influences technology acceptance significantly by relevant people (e.g. employees in organisations). Similarly, trust-related issues have been well documented in the existing literature on the adoption of Internet banking (cf. Yousafzai et al., 2009), where it is suggested that trust plays a vital role in the adoption of Internet banking. Thus, trust has been specifically found to be a significant factor in cases where humans interact and collaborate with AI-powered robots (Schaefer, 2013). However, this interaction between humans and robots is not without its 
challenges. Scholars have highlighted challenges such as human workers either expecting AI-powered machines like robots to do every task perfectly, leading to reduced communication (Schaefer, 2013), or starting to intervene in their tasks earlier than required due to the fear of them not doing the tasks efficiently (e.g. Demir et al., 2020). Also, prior studies have shown that human workers' behaviour and trust towards AI are influenced by whether it is in form of a physical robot or just virtual programme or process (e.g. Glickson and Wooolley, 2020). Also, some recent studies (e.g. Gillath et al., 2021) have referred to the importance of attachment in context of AI-human workers relationship and trust development. All these aspects concerning expectations and trust development can be challenging for HRM in organisations due to a rather lack of prior practice-based evidence on useful strategies in such circumstances due to the newness of topic. Hence, it is important to incorporate knowledge from related fields in order to develop and enrich HRM strategies in this concern.

For example, earlier studies have found organisational support an important factor in helping employees deal with new technology-related challenges and overcome resistance to their adoption (Mitchell et al., 2012; Sampson et al., 2020). This organisational support tends to manifest itself in the form of developing facilitating conditions and offering required training (Mitchell et al., 2012; Paruzel et al., 2020). It is indeed important for HR departments to ensure that a viable level of technology-specific competence in employees before they are introduced to work in teams comprising of humans and robots. However, recent studies have suggested that many firms are failing to adequately train their employees for interaction and collaboration with $\mathrm{AI}$ - resulting in making them not ready for future work, where this is expected to be a common sight (Ivanov and Webster, 2019).

Earlier mentioned facilitating conditions and training can potentially result in development of a certain level of attachment (bond) between human workers and AI especially if the need of attachment or dependency urge is mentioned by AI robot as it gives confidence boost to human workers (e.g. Gillath et al., 2021). Finally, one of the toughest challenges for the HR function in organisations relates to performance evaluation dynamics, especially in cases where humans and AI-enabled robots are both working as part of the same team. Due to this phenomenon's relative newness, there is a lack of specific HRM studies addressing this topic. However, we argue that HRM as a research area, as well as HR functions in organisations, can benefit from prior research done in areas such as computer gaming, where performance evaluation between human and AI gamers has been addressed from a range of perspectives (e.g. Kim et al., 2018). These studies have stressed the issues such as contextualising performance evaluation (e.g. Backlund et al., 2018), adjustable performance criteria incorporating human limitations (Canaan et al., 2019), especially the element of fatigue (Shen et al., 2019). HRM function in organisations where human workers interact, collaborate and perhaps compete with AI-enabled robots in the same teams will need to use such and other similar insights to develop a relatively fair performance appraisal system. This is expected to overcome hesitations and develop trust in such emerging technologies (Bitkina et al., 2020) in order to keep human workers motivated to continue interacting and collaborating with AI-enabled robots, as team members.

Table 1 presents a summary of key challenges and potential HRM strategies dealing with AI-human workers' teamwork interaction and collaboration in contemporary organisations.

\section{Conclusions, implications and future research directions \\ 4.1 Conclusions}

The key aim of this paper was to take a closer and critical look at the interaction between AI and human workers from an HRM lens by specifically focussing on the challenges organisations and workers encounter due to this relatively new phenomenon. Existing
$\mathrm{AI}$ and human workers interaction 
Human workers-AI team interaction dynamics

Workers' anxiety of working in the same team with AI-powered machines/robots (e.g. Wilson and Daugherty, 2018; Smids et al., 2020)

Trust between human workers and AI (e.g. Ivanov and Webster, 2019; Glickson and Woolley, 2020; Webster and Ivanov, 2020; Gillath et al., 2021)

Tasks expectations from each other (e.g. Schafer, 2013; Demir et al., 2020)

Performance evaluation of team members (e.g. Backlund et al., 2018; Kim et al., 2018)
Fear of losing jobs

Inability to communicate properly with AI-powered teammate who needs to be programmed
Resistance by some workers in accepting these robots as team members and stress of working in such a team
Human workers either underestimating or overestimating the potential of AI-powered team members

Human workers become tired, need to take rest, breaks and holidays, while AI-powered team members' performance tends not to be influenced by these aspects
Table 1.

Human workers and AI interaction at a team level: hurdles and potential HRM strategies
Potential HRM strategies/ interventions

Development of a clear communication protocol before such teams are introduced Training initiatives for the human workers

Ensuring a viable technological competence level of workers who are involved in such teams Developing a facilitating environment

Clearly mentioning the purpose of such teams and expected goals

Keeping the human workers in the communication loop about their jobs and potential future developments

Developing a clear teamwork communication protocol as that would remove ambiguities Clear communication of task specification, expected outputs and flow of tasks so that such hurdles can be addressed

Contextualising performance evaluation by incorporating human workers' limitations clearly in the performance evaluation frameworks at the team level and at the organisation level. HRM function can greatly benefit from computer gaming research where there are some developed framework for a relatively fair evaluation of human players compared to AI players

research and popular press have documented the potential advantages of utilising AI in organisations in terms of improving productivity and streamlining organisational processes and tasks (KPMG, 2019; Forbes, 2019). However, there are significant psychological barriers in adopting modern technologies due to the fear of workers losing their jobs and requiring additional training to use such technologies.

Based on a conceptual overview, this paper highlights that interaction and collaboration between human workers and robots are visible in a range of organisational functions, where both are working as team members. This gives rise to unique challenges for HRM function in contemporary organisations where they need to address workers' fear of working with AI, especially concerning future job loss and complicated dynamics associated with building trust between human workers and AI-enabled robots as team members. Along with these, human workers' task fulfilment expectations with their AI-enabled robot colleagues need to be carefully communicated and managed by HRM staff to maintain the collaborative spirit. We highlight that organisational support mechanisms such as facilitating environment, training opportunities and ensuring a viable technological competence level before 
organising human workers in teams with robots are important for organisations to reap the benefits from emerging technologies. Finally, we found that one of the toughest challenges for HRM relates to performance evaluation in teams where both humans and robots work side by side. We referred to the lack of existing frameworks to guide HRM function in this concern and stressed the possibility of taking insights from the computer gaming literature, where performance evaluation models have been developed to analyse humans' performance in the same context as AI.

\subsection{Theoretical and managerial implications}

The discussion offered in the current conceptual piece provides both theoretical and managerial implications. First, a key theoretical implication relates to the importance of developing specific theoretical paradigms that go beyond viewing AI from a functional usage perspective in HRM and offer specific insights concerning the challenges emanating from humans and AI working together in teams (cf. Tambe et al., 2019). Such paradigms will need to be contextualised and industry (sector) focussed, as the challenges as well as associated dynamics vary when human workers work with robots in assembly line manufacturing to when they are working together on a research and development project in the IT sector to their collaboration in customer service delivery settings. Also, incorporating multidisciplinarity is important for any theoretical work on AI and human workers interaction from an HRM focus as academic areas such as computer gaming, as well as robotics research, have a significant potential to offer insights due to their link to this context, as well as significant research already being done there from a technical perspective. In addition, key insights that are drawn from the technology acceptance model (e.g. Davis, 1989; Davis et al., 1989) and diffusion of innovations (e.g. Rogers, 1995) will provide an important understanding of the challenges related to the utilisation and acceptance of modern technologies in organisations.

A key managerial implication from the current paper relates to the importance of trust building and communication to overcome the challenges associated with human workers and AI interaction. A recent paper by Demir et al. (2020) found that AI-enabled machines, including robots, still need to be programmed to understand their team environment and effectively communicate with human co-workers. Hence, the burden of communication and trust-building in such teams still lies with human workers and managers. Therefore, the managers should clearly specify the goals and expected outcomes of such teams, along with a relatively clear explanation of performance evaluation criteria. Such endeavours are expected to result in the development of trust in the teams. Also, the facilitating environment dynamics mentioned earlier should be clearly visible in HRM strategies of the organisation where teams comprising of human and AI workers are becoming a visible part of the modern organisational landscape. Skills identification, as well as development strategies in such organisations, will also need to be further enhanced, as, in a hybrid working environment of human and AI workers, managers need to have a clear grasp of what specific skills are needed in both types, in order for the teams to achieve their goals. Beside managerial implications, the paper has important policy implications. Given that policymakers are encouraging the development of AI and emerging technologies related infrastructure - a case in point is China and several other developed markets that are aggressively investing in AI infrastructure. Therefore, policymakers need to invest in key skills, given that skills related to emerging technologies are still with most of the developed markets, and emerging and developing economies lack such skills. Adopting and leveraging emerging technologies such as AI and robots by organisations from various sectors may lead to fewer people commuting to work. As we have seen during the current pandemic, organisations are utilising emerging technologies for performing various functions and facilitating work from home. With this in

$\mathrm{AI}$ and human workers interaction 
IJM

43,1

mind, policymakers need to work closely with organisations and facilitate the development of sound HRM practices conducive to the utilisation and adoption of emerging technologies.

\subsection{Future research directions}

Our paper also offers important avenues for future research. First, future studies could collect longitudinal data and examine employees' reactions, both skilled and semi-skilled, to utilise emerging technologies such as AI and track the productivity gains through such technologies. Second, key decision-makers and boards' role can be important in the implementation and utilisation of emerging technologies. Thus, future studies need to examine the type of leadership styles conducive to utilising emerging technologies in the workplace. Third, future studies can empirically examine the touch challenges of emerging technologies such as AI in HRM context by analysing human workers' emotions and adjustment dynamics in teams where they are working with AI-powered robots. Fourth, future studies could examine how emerging technologies will shape the future of work, including workers' resilience and adaptability. Future studies need to explore the psychological issues related to emerging technologies and how various HR practices could mitigate employees' psychological problems associated with emerging technologies would provide useful insights. It should be noted that some barriers/hurdles mentioned in Table 1 possess high power to drive other barriers and may cause a domino effect in a system. Therefore, it will be insightful to explore the hierarchy and dependencies amongst the barriers to implementing AI in HRM to understand which barrier is the most influential and needs to be eliminated first. Finally, future research can examine the interactive effect of possible impending (resistance to change, fear of job loss, organisational inertia) and driving (training, conducive environment, collaboration, communication, performance improvement) forces on the interaction between $\mathrm{AI}$ and human workers.

\section{References}

Analytica, O. (2020), "Gpt-3 AI language tool calls for cautious optimism”, Emerald Expert Briefings. doi: 10.1108/OXAN-DB256373/full/html.

Anand, G., Ward, P.T. and Tatikonda, M.V. (2010), "Role of explicit and tacit knowledge in Six Sigma projects: an empirical examination of differential project success", Journal of Operations Management, Vol. 28 No. 4, pp. 303-315.

Arslan, A., Ruman, A., Naughton, S. and Tarba, S.Y. (2021), "Human dynamics of automation and digitalisation of economies: discussion on the challenges and opportunities", in Park, S.H., Gonzalez-Perez, M.A. and Floriani, D.E. (Eds), The Palgrave Handbook of Corporate Sustainability in the Digital Era, Palgrave Macmillan (Springer Nature), pp. 613-629.

Arthanat, S., Vroman, K.G., Lysack, C. and Grizzetti, J. (2019), "Multi-stakeholder perspectives on information communication technology training for older adults: implications for teaching and learning", Disability and Rehabilitation: Assistive Technology, Vol. 14 No. 5, pp. 453-461.

Avolio, B.J., Sosik, J.J., Kahai, S.S. and Baker, B. (2014), "E-leadership: re-examining transformations in leadership source and transmission", The Leadership Quarterly, Vol. 25 No. 1, pp. 105-131.

Backlund, P., Maurin Söderholm, H., Engström, H., Andersson Hagiwara, M. and Lebram, M. (2018), "Breaking out of the bubble putting simulation into context to increase immersion and performance", Simulation and Gaming, Vol. 49 No. 6, pp. 642-660.

Bawden, D. and Robinson, L. (2009), "The dark side of information: overload, anxiety and other paradoxes and pathologies", Journal of Information Science, Vol. 35 No. 2, pp. 180-191.

Bednar, P.M. and Welch, C. (2020), "Socio-technical perspectives on smart working: creating meaningful and sustainable systems", Information Systems Frontiers, Vol. 22, pp. 281-298. 
Bitkina, O.V., Jeong, H., Lee, B.C., Park, J., Park, J. and Kim, H.K. (2020), "Perceived trust in artificial intelligence technologies: a preliminary study", Human Factors and Ergonomics in Manufacturing and Service Industries, Vol. 30 No. 4, pp. 282-290.

Canaan, R., Salge, C., Togelius, J. and Nealen, A. (2019), "Leveling the playing field: fairness in AI versus human game benchmarks", Proceedings of the 14th International Conference on the Foundations of Digital Games, pp. 1-8.

Castelfranchi, C. and Falcone, R. (2010), Trust Theory: A Socio-Cognitive and Computational Model, John Wiley \& Sons, Hoboken, NJ.

CIO (2020), "Transforming HR through AI: how AI will help plug skill gaps in organisations", available at: https://cio.economictimes.indiatimes.com/news/next-gen-technologies/ transforming-hr-through-ai-how-ai-will-help-plug-skill-gaps-in-organisations/80020641 (accessed 18 January 2021).

Coupe, T. (2019), "Automation, job characteristics and job insecurity", International Journal of Manpower, Vol. 40 No. 7, pp. 1288-1304.

Davis, F.D. (1989), "Perceived usefulness, perceived ease of use, and user acceptance of information technology”, MIS Quarterly, Vol. 13 No. 3, pp. 319-340.

Davis, F.D., Bagozzi, R.P. and Warshaw, P.R. (1989), "User acceptance of computer technology: a comparison of two theoretical models", Management Science, Vol. 35 No. 8, pp. 982-1003.

Davison, H.K., Maraist, C. and Bing, M.N. (2011), "Friend or foe? The promise and pitfalls of using social networking sites for HR decisions", Journal of Business and Psychology, Vol. 26 No. 2, pp. 153-159.

Demir, M., McNeese, N.J. and Cooke, N.J. (2020), "Understanding human-robot teams in light of allhuman teams: aspects of team interaction and shared cognition", International Journal of Human-Computer Studies, Vol. 140, 102436.

Derks, D., Van Duin, D., Tims, M. and Bakker, A.B. (2015), "Smartphone use and work-home interference: the moderating role of social norms and employee work engagement", Journal of Occupational and Organisational Psychology, Vol. 88 No. 1, pp. 155-177.

Driskell, J.E., Salas, E. and Driskell, T. (2018), "Foundations of teamwork and collaboration”, American Psychologist, Vol. 73 No. 4, pp. 334-38.

Evjemo, L.D., Gjerstad, T., Grøtli, E.I. and Sziebig, G. (2020), "Trends in smart manufacturing: role of humans and industrial robots in smart factories", Current Robotics Reports, Vol. 1 No. 2, pp. 35-41.

Fitzgerald, M., Kruschwitz, N., Bonnet, D. and Welch, M. (2014), "Embracing digital technology: a new strategic imperative", MIT Sloan Management Review, Vol. 55 No. 2, pp. 1-12.

Forbes (2019), "Ten HR trends in the age of artificial intelligence", available at: https://www.forbes. com/sites/jeannemeister/2019/01/08/ten-hr-trends-in-the-age-of-artificial-intelligence/? sh=5794538c3219 (accessed 14 April 2021).

Gibbs, C., MacDonald, F. and MacKay, K. (2015), "Social media usage in hotel human resources: recruitment, hiring and communication", International Journal of Contemporary Hospitality Management, Vol. 27 No. 2, pp. 170-184.

Gillath, O., Ai, T., Branicky, M.S., Keshmiri, S., Davison, R.B. and Spaulding, R. (2021), "Attachment and trust in artificial intelligence", Computers in Human Behavior, Vol. 115, 106607.

Glikson, E. and Woolley, A.W. (2020), "Human trust in artificial intelligence: review of empirical research", Academy of Management Annals, Vol. 14 No. 2, pp. 627-660.

Golembiewski, R. (2019), "Development, transition, or transformation", in Golembiewski, R. (Ed.), Handbook of Organisational Consultation, 2nd ed., Routledge, New York, NY, pp. 60-76.

Harms, P., Credé, M., Tynan, M., Leon, M. and Jeung, W. (2017), "Leadership and stress: a metaanalytic review", The Leadership Quarterly, Vol. 28 No. 1, pp. 178-194.

$\mathrm{AI}$ and human workers interaction 
IJM

43,1

Harrington, K.V., McElroy, J.C. and Morrow, P.C. (1990), "Computer anxiety and computer-based training: a laboratory experiment", Journal of Educational Computing Research, Vol. 6 No. 3, pp. 343-358.

Henfridsson, O., Mathiassen, L. and Svahn, F. (2014), "Managing technological change in the digital age: the role of architectural frames", Journal of Information Technology, Vol. 29 No. 1, pp. 27-43.

Hmoud, B. and Laszlo, V. (2019), "Will artificial intelligence take over human resources recruitment and selection", Network Intelligence Studies, Vol. 7 No. 13, pp. 21-30.

Holland, P. and Anne Bardoel, A. (2016), "The impact of technology on work in the twenty-first century: exploring the smart and dark side", The International Journal of Human Resource Management, Vol. 27 No. 21, pp. 2579-2581.

Hudson, S., Matson-Barkat, S., Pallamin, N. and Jegou, G. (2019), "With or without you? Interaction and immersion in a virtual reality experience", Journal of Business Research, Vol. 100, pp. $459-468$.

Ivanov, S. and Webster, C. (2019), Robots, Artificial Intelligence and Service Automation in Travel, Tourism and Hospitality, Emerald Publishing, Bingley.

Kaplan, A. and Haenlein, M. (2019), "Siri, Siri, in my hand: who's the fairest in the land? On the interpretations, illustrations, and implications of artificial intelligence", Business Horizons, Vol. 62 No. 1, pp. 15-25.

Kim, M.J., Kim, K.J., Kim, S. and Dey, A.K. (2018), "Performance evaluation gaps in a real-time strategy game between human and artificial intelligence players", IEEE Access, Vol. 6, pp. 13575-13586.

KPMG (2019), "Rise of the humans 3: shaping the workforce of the future", available at: https://assets. $\mathrm{kpmg} / \mathrm{content/dam/kpmg/xx/pdf/2018/11/rise-of-the-humans-2019.pdf.}$

Larivière, B., Bowen, D., Andreassen, T.W., Kunz, W., Sirianni, N.J., Voss, C. and De Keyser, A. (2017), "'Service encounter 2.0': an investigation into the roles of technology, employees and customers", Journal of Business Research, Vol. 79, pp. 238-246.

Libert, K., Mosconi, E. and Cadieux, N. (2020), "Human-machine interaction and human resource management perspective for collaborative robotics implementation and adoption", Proceedings of the 53rd Hawaii International Conference on System Sciences, available at: https:// scholarspace.manoa.hawaii.edu/bitstream/10125/63805/0053.pdf.

Maitlis, S. and Ozcelik, H. (2004), "Toxic decision processes: a study of emotion and organisational decision making", Organization Science, Vol. 15 No. 4, pp. 375-393.

Malik, A., Budhwar, P. and Srikanth, N.R. (2020), "Gig economy, 4IR and artificial intelligence: rethinking strategic HRM", Human \& Technological Resource Management (HTRM): New Insights into Revolution 4.0, Emerald Publishing, Bingley.

Mariappanadar, S. and Aust, I. (2017), "The dark side of overwork: an empirical evidence of social harm of work from a sustainable HRM perspective", International Studies of Management and Organization, Vol. 47 No. 4, pp. 372-387.

Mattessich, P.W. and Monsey, B.R. (1992), "Collaboration: what makes it work", A Review of Research Literature on Factors Influencing Successful Collaboration, Wilder Foundation, Amherst HSt. Paul, MN.

Mikkelsen, A., Øgaard, T., Lindøe, P.H. and Olsen, O.E. (2002), "Job characteristics and computer anxiety in the production industry", Computers in Human Behavior, Vol. 18 No. 3, pp. 223-239.

Mitchell, J.I., Gagné, M., Beaudry, A. and Dyer, L. (2012), "The role of perceived organisational support, distributive justice and motivation in reactions to new information technology", Computers in Human Behavior, Vol. 28 No. 2, pp. 729-738.

Mohanta, B., Nanda, P. and Patnaik, S. (2020), "Management of v. UCA (volatility, uncertainty, complexity and ambiguity) using machine learning techniques in industry 4.0 paradigm", in Patnaik, S. (Ed.), New Paradigm of Industry 4.0: Internet of Things, Big Data \& Cyber-Physical Systems, Springer International Publishing, Cham, pp. 1-24. 
Moore, T. (2018), The Disposable Workforce: Worker Displacement and Employment Instability in America, Routledge, New York, NY.

Mosco, V. (2016), "Marx in the cloud", Marx in the Age of Digital Capitalism, Brill, Leiden, pp. 516-535.

Nica, E., Miklencicova, R. and Kicova, E. (2019), “Artificial intelligence-supported workplace decisions: big data algorithmic analytics, sensory and tracking technologies, and metabolism monitors", Psychosociological Issues in Human Resource Management, Vol. 7 No. 2, pp. 31-36.

Novak, E. and Wisdom, S. (2018), "Effects of 3D printing project-based learning on preservice elementary teachers' science attitudes, science content knowledge, and anxiety about teaching science", Journal of Science Education and Technology, Vol. 27 No. 5, pp. 412-432.

Okumus, F., Bilgihan, A., Ozturk, A.B. and Zhao, X. (2017), "Identifying and overcoming barriers to deployment of information technology projects in hotels", Journal of Organizational Change Management, Vol. 30 No. 5, pp. 744-766.

Paruzel, A., Bentler, D., Schlicher, K.D., Nettelstroth, W. and Maier, G.W. (2020), "Employees first, technology second", Zeitschrift für Arbeits-und Organisationspsychologie, Vol. 64 No. 1, pp. 46-57.

Petriglieri, G., Ashford, S.J. and Wrzesniewski, A. (2019), "Agony and ecstasy in the gig economy: cultivating holding environments for precarious and personalised work identities", Administrative Science Quarterly, Vol. 64 No. 1, pp. 124-170.

Peysakhovich, A. and Naecker, J. (2017), "Using methods from machine learning to evaluate behavioral models of choice under risk and ambiguity", Journal of Economic Behavior and Organization, Vol. 133, pp. 373-384.

Pueyo, S. (2018), "Growth, degrowth, and the challenge of artificial superintelligence”, Journal of Cleaner Production, Vol. 197, pp. 1731-1736.

Richards, G., Yeoh, W., Chong, A.Y.L. and Popovič, A. (2019), "Business intelligence effectiveness and corporate performance management: an empirical analysis", Journal of Computer Information Systems, Vol. 59 No. 2, pp. 188-196.

Rodney, H., Valaskova, K. and Durana, P. (2019), "The artificial intelligence recruitment process: how technological advancements have reshaped job application and selection practices", Psychosociological Issues in Human Resource Management, Vol. 7 No. 1, pp. 42-47.

Rogers, E. (1995), Diffusion of Innovations, 4th ed., Free Press, New York.

Sampson, J.P., Kettunen, J. and Vuorinen, R. (2020), "The role of practitioners in helping persons make effective use of information and communication technology in career interventions", International Journal for Educational and Vocational Guidance, Vol. 20 No. 1, pp. 191-208.

Schaefer, K. (2013), "The perception and measurement of human-robot trust", PhD Thesis, University of Central Florida, available at: http://etd.fcla.edu/CF/CFE0004931/Schaefer_Kristin_E_201308_ PhD.pdf.

Seeber, I., Bittner, E., Briggs, R.O., de Vreede, T., De Vreede, G.J., Elkins, A., Maier, R., Merz, A.B., Oeste-Reiß, S., Randrup, N., Schwabe, G. and Söllner, M. (2020), "Machines as teammates: a research agenda on AI in team collaboration", Information and Management, Vol. 57 No. 2, 103174, doi: 10.1016/j.im.2019.103174.

Serban, A., Yammarino, F.J., Dionne, S.D., Kahai, S.S., Hao, C., Mchugh, K.A., ... and Peterson, D.R. (2015), "Leadership emergence in face-to-face and virtual teams: a multi-level model with agentbased simulations, quasi-experimental and experimental tests", The Leadership Quarterly, Vol. 26 No. 3, pp. 402-418.

Shen, J., Zhang, C.J., Jiang, B., Chen, J., Song, J., Liu, Z., He, Z., Wong, S.Y., Fang, P.H. and Ming, W.K. (2019), "Artificial intelligence versus clinicians in disease diagnosis: systematic review", JMIR Medical Informatics, Vol. 7 No. 3, e10010, doi: 10.2196/10010.

Sivathanu, B. and Pillai, R. (2018), "Smart HR 4.0 - how industry 4.0 is disrupting HR", Human Resource Management International Digest, Vol. 26 No. 4, pp. 7-11.
$\mathrm{AI}$ and human workers interaction 
IJM

43,1

88

Smids, J., Nyholm, S. and Berkers, H. (2020), "Robots in the workplace: a threat to-or opportunity for-meaningful work?”, Philosophy and Technology, Vol. 33 No. 3, pp. 503-522.

Spencer, A.J., Buhalis, D. and Moital, M. (2012), "A hierarchical model of technology adoption for small owner-managed travel firms: an organisational decision-making and leadership perspective", Tourism Management, Vol. 33 No, 5, pp. 1195-1208.

Strohmeier, S. and Piazza, F. (2015), "Artificial intelligence techniques in human resource management - a conceptual exploration”, Intelligent Techniques in Engineering Management, Springer, Cham, pp. 149-172.

Sutherland, W., Jarrahi, M.H., Dunn, M. and Nelson, S.B. (2020), "Work precarity and gig literacies in online freelancing", Work, Employment and Society, Vol. 34 No. 3, pp. 457-475.

Tambe, P., Cappelli, P. and Yakubovich, V. (2019), "Artificial intelligence in human resources management: challenges and a path forward", California Management Review, Vol. 61 No. 4, pp. 15-42.

Tsarouchi, P., Michalos, G., Makris, S., Athanasatos, T., Dimoulas, K. and Chryssolouris, G. (2017), "On a human-robot workplace design and task allocation system", International Journal of Computer Integrated Manufacturing, Vol. 30 No. 12, pp. 1272-1279.

van den Heuvel, S. and Bondarouk, T. (2017), "The rise (and fall?) of HR analytics: a study into the future application, value, structure, and system support", Journal of Organizational Effectiveness: People and Performance, Vol. 4 No. 2, pp. 157-178.

Vrontis, D., Christofi, M., Pereira, V., Tarba, S., Makrides, A. and Trichina, E. (2021), "Artificial intelligence, robotics, advanced technologies and human resource management: a systematic review", International Journal of Human Resource Management, Early view. doi: 10.1080/ 09585192.2020.1871398.

Webster, C. and Ivanov, S. (2020), "Robotics, artificial intelligence, and the evolving nature of work", Digital Transformation in Business and Society, Palgrave Macmillan, Cham, pp. 127-143.

Webster, J. and Martocchio, J.J. (1992), "Microcomputer playfulness: development of a measure with workplace implications”, MIS Quarterly, Vol. 16 No. 2, pp. 201-226.

Wilson, H.J. and Daugherty, P.R. (2018), "Collaborative intelligence: humans and AI are joining forces", Harvard Business Review, Vol. 96 No. 4, pp. 114-123.

Yampolskiy, R.V. (2015), Artificial Superintelligence: A Futuristic Approach, Routledge, Oxon.

Yousafzai, S., Pallister, J. and Foxall, G. (2009), "Multidimensional role of trust in Internet banking adoption”, The Service Industries Journal, Vol. 29 No. 5, pp. 591-605.

\section{Corresponding author}

Ahmad Arslan can be contacted at: ahmad.arslan@oulu.fi

For instructions on how to order reprints of this article, please visit our website:

www.emeraldgrouppublishing.com/licensing/reprints.htm

Or contact us for further details: permissions@emeraldinsight.com 